\title{
Injuries and their relation to potential hazards in child day care
}

\author{
Peter Cummings, Frederick P Rivara, Janice Boase, Jean K MacDonald
}

\begin{abstract}
Objectives-To prospectively determine the incidence rate of injuries that required medical attention among children in day care and to identify possible hazards related to these injuries.
\end{abstract}

Setting-King County, Washington.

Methods-Prospective cohort study of children in a sample of licensed day care facilities.

Results-From 1 July 1992 to 30 June 1993, 53 medically attended injuries were reported by 133 day care sites; incidence rate 1.9 per 100000 hours of day care attendance. The rate of injury in 91 small family day care homes was essentially the same as that in 42 larger day care centers; relative rate $1.0(95 \%$ confidence interval 0.6 to 1.9 ). Injuries that required sutures accounted for $39 \%$ of the cases, while $17 \%$ required a cast, splint, or sling. No child was hospitalized. Sixty nine sites were inspected and all had potentially correctable physical hazards, with a median of 15 hazards per site (range 7 to 26). These potential hazards had little relationship to the risk of injury and a case-by-case review identified only two injuries that might have been prevented by a more energy absorbent playground surface.

Department of Epidemiology, School of Public Health and Community Medicine and Harborview Injury Prevention and Research Center, University of

Washington, Seattle, WA, USA

$P$ Cummings

Department of Pediatrics, School of Medicine and

Harborview Injury

Prevention and

Research Center,

University of

Washington, Seattle,

WA, USA

FP Rivara

Seattle-King County Department of Public Health, Seattle, WA,

USA

J Boase

JK MacDonald

Correspondence to: Dr Peter Cummings, Harborview Injury

Prevention and Research

Prevention and Research

Center, 325 Ninth Avenue,

98104-2499, USA.
Conclusions-The incidence of medically attended injuries found in this study is consistent with other studies from the United States. Most injuries were minor and had little relation to physical hazards at day care locations.

(Injury Prevention 1996; 2: 105-108)

Keywords: day care, injury.

Previous studies of injuries in day care have varied from those focusing on all injuries, no matter how trivial, ${ }^{1-5}$ to studies that only counted injuries that received medical attention. $^{6-12}$ In the United States, reported rates of medically attended injuries range from 1.5 to 2.5 per 100000 hours of exposure at day care. ${ }^{6-10} \mathrm{~A}$ few studies have provided evidence that the rate of medically attended injuries in day care is less than the rate at home. ${ }^{7-912}$

In 1992 the Seattle-King County Department of Public Health initiated a voluntary reporting system in a sample of licensed day care settings. Participating day care operators were asked to report on all illnesses and injuries. This paper reviews the medically attended injuries reported over a one year period. Slightly over half of the reporting day care sites were surveyed for physical hazards and this information was analyzed to see if these potential hazards were related to the risk of injury.

\section{Methods}

CASE ASCERTAINMENT

King County, which includes the city of Seattle, is the largest county in Washington State, with a population of 1587700 in $1993 . .^{13}$ In 1992, there were 2188 day care facilities licensed in King County. Facilities were selected randomly and invited to join the study, with a goal of recruiting 200 sites that would prospectively report injuries occurring between 1 July 1992 and 30 June 1993. Providers were not asked to participate unless they provided day care to children less than 5 years of age and planned to remain open during the study period. At the start of the reporting period, half the participating sites were randomly selected to undergo an inspection. Observations were recorded on a survey form to assess the presence of 28 potential indoor hazards (for example hot tap water $>120^{\circ} \mathrm{F}$ ) and 40 potential outside hazards (for example climbing equipment $\geqslant 7.5$ feet in height).

During the study period each day care provider was asked to complete a form which gave the actual hours of day care provided each week, stratified by child's age. Providers were also asked to report, by phone and mail, any injury to a child that involved medical attention. Medical attention was defined as a call or visit to a nurse, physician, dentist, clinic, or hospital. When an injury was reported, the day care provider was interviewed by phone to obtain information about the circumstances and nature of the injury and its treatment. For each such report, we sought permission from the day care provider to contact the parents, and when this was obtained, we attempted to phone the parents to confirm that the child received medical attention and to have them complete a questionnaire concerning further details about the injury and treatment.

\section{ANALYSIS}

Injuries were categorized by age and sex of the victim, circumstances of the injury, and characteristics of the injury and treatment. Total and age specific rates of injury per 100000 hours of day care exposure were calculated. We compared injury rates for small day care homes, which by law have 12 or fewer children, and larger day care centers, which have 13 or more children and are almost always in facilities 
other than residential homes. ${ }^{1415}$ Poisson regression was used to calculate relative incidence estimates ${ }^{16}$ the association between the total number of potential physical hazards and the incidence of injury was explored using various transformations of the data on number of hazards, ${ }^{17}$ and forward stepwise variable selection was used to assess the association between items in the baseline hazard inspection and the subsequent risk of injury.

\section{Results}

Ultimately, 1107 day care facilities, slightly over half of all licensed day care sites in the county, were selected for possible participation in the study. Of these, 145 facilities could not be physically located, 223 were planning to close, and 51 did not provide care for children under 5 years of age. Of the remaining 688 selected sites, 255 agreed to participate and only 133 $(19 \%$ of the eligible providers) submitted reports of hours of attendance during the study period. Many day care operators found the reporting burdensome and only 25 operators submitted reports for $\geqslant 50$ weeks. Day care locations with greater numbers of children were over-represented in the sample compared with all day care providers in the county.

During the one year study period, day care staff reported a total of 56 injuries that they believed required medical attention. Phone follow up with parents revealed that three children had not received medical attention, leaving a total of 53 injuries for analysis. Children aged 1 and 2 years accounted for slightly over half of all the injuries and males accounted for $55 \%$. Complete age specific hours of attendance were reported by 14 day care operators $(11 \%)$. An additional 93 sites $(70 \%)$ reported age specific attendance hours for some time period; for other periods, an estimate was made based on the average weekly hours of day care at that site. For the remaining 26 locations, hours of day care were estimated based on the sites' licensed capacity and the average number of hours per child for all sites.

A total of 2738279 hours of day care attendance were reported or estimated, resulting in a rate of medically attended injuries of 1.9 per 100000 hours of day care attendance $(95 \%$ confidence interval (CI) 1.4 to $2 \cdot 5$ ). Age specific rates of injury are lowest for infants, are more than fourfold greater for children 1-2 years of age, fall almost to infant levels for 3 and 4 year old children, and rise again for children over age 5 years (table 1 ).

Table 1 Age specific rates of injuries that received medical attention in King County, $W A$

\begin{tabular}{llcll}
\hline $\begin{array}{l}\text { Age group } \\
\text { (years) }\end{array}$ & $\begin{array}{l}\text { No of } \\
\text { injured children }\end{array}$ & $\begin{array}{l}\text { Hours of day } \\
\text { care attendance }\end{array}$ & $\begin{array}{l}\text { Injuries per } \\
100 \text { 000 hourst }\end{array}$ & $95 \%$ CI \\
\hline$<1$ & 1 & 137389 & 0.7 & 0.0 to $4 \cdot 1$ \\
1 and 2 & 27 & 811240 & 3.3 & 2.2 to 4.9 \\
3 and 4 & 12 & 1109709 & $1 \cdot 1$ & 0.6 to 1.9 \\
$\geqslant 5$ & 13 & 587844 & $2 \cdot 2$ & 1.2 to 3.8 \\
All ages & 53 & 2738279 & 1.9 & 1.5 to 2.5
\end{tabular}

*Total hours are greater than the age specific hours because 92097 attendance hours $(3.4 \%$ of the total) were reported for children of unknown age. $+A$ test for heterogeneity of the age specific incidence rates was statistically significant $(p=0.01)$
The age adjusted rate of medically attended injury in 91 small day care homes $(\leqslant 12$ children) was the same as that for 42 larger day care centers ( $\geqslant 13$ children): rate ratio $1.0(95 \%$ CI 0.6 to 1.9$)$. Assuming that attendance in day care was evenly divided by sex, the relative rate of injury was $1.2(95 \%$ CI 0.7 to $2 \cdot 1)$ for boys compared with girls.

Specific information could not be obtained concerning some aspects of some injuries. Sometimes the day care operators were not certain how the injury occurred. In some situations the parents either could not be reached for an interview or the interview was refused; interview information was obtained for 36 cases $(68 \%)$. Only five injuries $(9 \%)$ were related to climbers, while 21 injuries involved collisions with, or falls onto, ordinary furniture (tables, chairs) (table 2). Injuries occurred more frequently indoors than outdoors. Falls were involved in $70 \%$ of all injuries.

Injury to some part of the face or head accounted for $72 \%$ of the total (table 2). Sutures were needed by $39 \%$, while $17 \%$ received a cast, splint, or sling. One child had outpatient surgery for fracture reduction, but no child was hospitalized. A parent missed one day of work for $29 \%$ of the cases, and two days for $12 \%$ of the injuries.

Table 2 Circumstances and characteristics of day care injuries that required medical attention (data missing from some categories

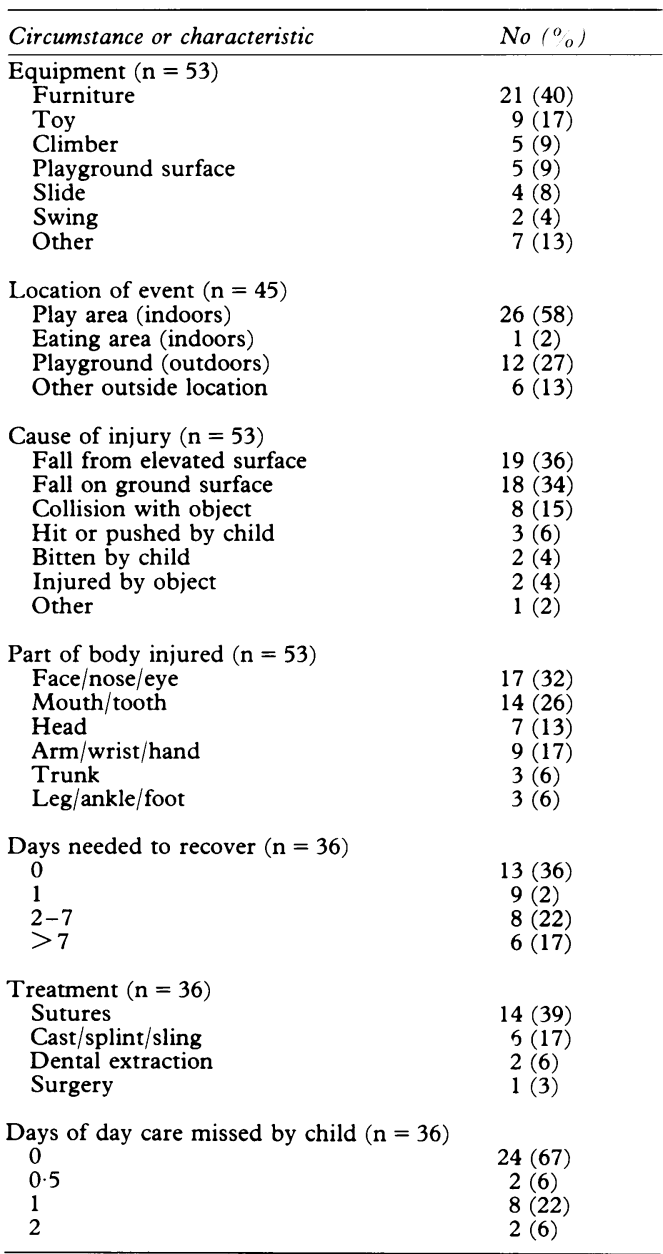


We attempted to relate the survey of potential hazards to the risk of subsequent injury. Because not all day care locations were visited and not all places that had inspections actually contributed data, we obtained both indoor and outdoor hazard survey data for 67 sites with 36 injury events. There were 68 hazard items that could be classified as present or absent; all locations had at least some potential hazards, with a median of 15 (range 7 to 26). We ranked sites by their total number of hazards and divided them into three groups with roughly equal amounts of day care exposure time: locations with $<13$ hazards, 13 to 18 hazards, and $>18$ hazards. There was no clear tendency for the relative risk of injury to increase across these three groups: compared with sites with $<13$ hazards, sites with 13 to 18 hazards had a relative risk for injury of $0.6(95 \% \mathrm{CI} 0.2$ to 1.6$)$ and sites with $>18$ hazards had a relative risk of $1.7(95 \%$ CI 0.8 to 3.5$)$; the test for a trend across these categories was not statistically significant $(p=0 \cdot 1)$. Other transformations of the number of physical hazards (log, square root, first order polynomial, etc) showed no statistically significant association between the number of potential hazards and the incidence of injuries.

We also attempted to measure the association of individual possible hazards with the risk of injury. The single item most closely associated with risk of injury was lack of a smoke detector; the relative risk of injury was $5.3(95 \% \mathrm{CI} 2.6$ to 10.6) in facilities without a smoke detector compared with those with this device. As no child had an injury due to smoke or fire, this association is not likely to be causal. When we eliminated lack of a smoke detector as a candidate variable, two potential hazards were statistically associated with injury: swing without safety straps for children less than 3 years of age and entrapment spaces in a merry-goround. Neither of these potential hazards, however, was involved in any of the identified injuries. In a case-by-case review, only two injuries could be related to physical hazards: a 4 year old child who fell four feet to pea gravel that was only three inches deep and suffered a fractured elbow, and a 2 year old child who fell three feet to concrete and suffered a possible concussion. Both these injuries might have been prevented by softer surfacing material.

\section{Discussion}

Over a one year interval, a sample of day care providers were asked to report all injuries that

Table 3 Incidence of medically attended injuries to children in day care from reported studies

\begin{tabular}{|c|c|c|c|c|}
\hline Study site & Method of ascertainment & $\begin{array}{l}\text { No of } \\
\text { injuries }\end{array}$ & $\begin{array}{l}\text { Age range } \\
\text { (years) }\end{array}$ & $\begin{array}{l}\text { Incidence per } \\
100000 \text { hours }\end{array}$ \\
\hline $\begin{array}{l}\text { Maryland } \\
\text { Atlanta }^{7} \\
\text { Seattle }^{8}\end{array}$ & $\begin{array}{l}\text { Telephone survey of centers } \\
\text { Monthly reports from day care operators } \\
\text { Injuries identified by a prepaid health } \\
\text { plan }\end{array}$ & $\begin{array}{r}18 \\
143 \\
29\end{array}$ & $\begin{array}{l}2-6 \\
0-12 \\
0-5\end{array}$ & $\begin{array}{l}2 \cdot 4 \\
1.8 \\
2 \cdot 5\end{array}$ \\
\hline $\begin{array}{l}\text { USA }^{9} \\
\text { USA }^{10} \\
\text { Norway } \\
{ }^{12}\end{array}$ & $\begin{array}{l}\text { Telephone survey of parents } \\
\text { Telephone survey of day care operators } \\
\text { Hospital and emergency department } \\
\text { records }\end{array}$ & $\begin{array}{c}? \\
566 \\
96\end{array}$ & $\begin{array}{l}0-4 \\
? \\
0.5-6\end{array}$ & $\begin{array}{l}2.2 \\
1.5 \\
1.3\end{array}$ \\
\hline This study & Reports from day care operators & 53 & $0-10$ & 1.9 \\
\hline
\end{tabular}

required medical attention. The incidence rate of medically attended injuries was 1.9 per 100000 hours of day care. This estimate could be biased upwards if day care operators erroneously reported that injured children had received medical attention. In 39 cases where we were able to interview a parent, three $(8 \%)$ reported that no medical care had been sought for the child, and we eliminated those reports. Alternatively, we may have underestimated the true incidence of injury if some day care operators either failed to report that a medically attended injury had occurred or were unaware that a child was taken for treatment after the child left their care. Although we attempted to randomly sample day care locations, most operators either refused to participate or failed to contribute data because they found the reporting system too onerous; therefore, our injury rate estimates may not accurately represent the experience of all King County day care settings.

Nevertheless, the injury rate we estimated is close to that reported by other studies of medically treated day care injuries (table 3). Landman and Landman telephoned Maryland day care centers and asked if any injuries had occurred in the previous five days. ${ }^{6}$ If we assume that the children in that study were in day care for an average of eight hours per day, the incidence rate is 2.4 per 100000 hours. Sacks and co-workers asked Atlanta day care centers to report medically attended injuries at monthly intervals and found an incidence of 1.8 per 100000 hours. $^{7}$ Similarly, a study of children attending a medical clinic in Seattle calculated a rate of 2.5 injuries per 100000 hours of day care. ${ }^{8}$ A nationwide telephone survey of households estimated the rate of injury for 2250 children under age 5 , and found an incidence of 2.2 per 100000 hours of day care. ${ }^{9}$ A nationwide telephone survey of day care centers asked about injuries in the previous two months and reported an incidence of 1.5 per 100000 hours. ${ }^{10}$ All these studies of medically attended injuries in United States day care settings found rates between 1.5 and 2.5 per 100000 hours, despite different ascertainment sources and methods. In Stavanger, Norway, the incidence of injuries in day care was 1.3 per 100000 , not too dissimilar from the US reports. ${ }^{12}$

The age specific injury rates in our study agree fairly closely with a similar study from Atlanta. ${ }^{7}$ Both found the lowest rates in children less than 1 year of age, and the highest rates for 1-2 year old children and those over age 5 years. These findings are generally consistent with an earlier Seattle study, but the number of cases was small in that study, making the age specific rates less stable. ${ }^{8}$ We found that boys were slightly more at risk for injury (relative risk estimate of 1.2). Although the confidence interval around this estimate included 1 , it was consistent with the estimate of 1.14 found in Atlanta day care centers. ${ }^{7}$

In Atlanta, $54 \%$ of all day care injuries occurred outdoors and $47 \%$ were on a playground. ${ }^{7}$ A national survey reported that $51 \%$ of medically attended injuries occurred in a 
playground. ${ }^{10}$ In contrast, we found that only $40 \%$ of all injuries happened outside and only $27 \%$ were in a playground. This lower proportion of outdoor and playground injuries might be due to chance, but it also may reflect less use of outdoor locations during inclement Northwest weather. Indoor play areas and outdoor playgrounds together accounted for $84 \%$ of the injuries with a known location in this study; the remaining injuries were either in a dining area or other outdoor locations.

An analysis of playground injuries in Atlanta day care centers revealed that centers with a greater number of playground hazards were more likely to report a medically attended injury. ${ }^{18}$ The Atlanta authors also found that taller climbing equipment was associated with fall injuries. These estimates were not adjusted for hours of exposure to day care.

We found little evidence that the number of potential hazards identified by an inspection at the start of the study had any relationship to the risk of injury. While a larger study with more injuries might have more power to evaluate the risk associated with physical hazards, most day care injuries may have little relationship to these potential hazards. We identified only two injuries that might have been due to a physical hazard, whereas most injuries were either due to falls at ground level or collisions with other children and with ordinary furniture. Other studies suggest that day care is relatively safe compared with the home,$^{8-1012}$ and the injury rate estimated in our data is consistent with that conclusion. In addition, we found no evidence that the risk of injury differed between day care homes and larger day care centers.

The published studies suggest to us that the day care environment is relatively safe for children and current regulations regarding day care safety may be adequate. Large reductions in serious childhood injuries are unlikely to result from further regulation of day care.
Furthermore, surveillance of day care injuries is difficult and time consuming and may not be worth the effort.

This work was supported by grants (U50/CCU007160 and R49/CCR002570) from the Centers for Disease Control and Prevention.

1 Solomons HC, Lakin JA, Snider BC, Paredes-Rojas RR. Is day care safe for children? Accident records reviewed. Child Health Care 1982; 10: 90-3.

2 Elardo R, Solomons HC, Snider BC. An analysis of accidents at a day care center. Am $\mathcal{F}$ Orthopsychiatry 1987; 57: $60-5$.

3 Chang A, Lugg MM, Nebedum A. Injuries among preschool children enrolled in day care centers. Pediatrics 1989; 83: 272-7.

4 Leland NL, Garrard J, Smith DK. Injuries to preschool-age children in day-care centers. A retrospective record review. Am f Dis Child 1993; 147: 826-31.

5 Alkon A, Genevro JL, Kaiser PJ, Tschann JM, Chesney M Boyce WT. Injuries in child-care centers: rates, severity, and etiology. Pediatrics 1994; 94 (suppl 6, part 2): 1043-6.

6 Landman PF, Landman GB. Accidental injuries in childre in day-care centers. Am $\mathcal{J}$ Dis Child 1987; 141: 292-3.

7 Sacks JJ, Smith JD, Kaplan KM, Lambert DA, Sattin RW, Sikes K. The epidemiology of injuries in Atlanta day-care centers. FAMA 1989; 262: 1641-5.

8 Rivara FP, DiGuiseppi C, Thompson RS, Calonge N. Risk of injury to children less than 5 years of age in day care of injury to children less than 5 years of age in day care

9 Gunn WJ, Pinsky PF, Sacks JJ, Schonberger LB. Injuries and poisonings in out-of-home child care and home care.
and Am f Dis Child 1991; 145: 779-81.

10 Briss PA, Sacks JJ, Addiss DG, Kresnow M-J, O'Neill J. A nationwide study of the risk of injury associated with day care center attendance. Pediatrics 1994; 93: 364-8.

11 Mackenzie SG, Sherman GJ. Day-care injuries in the dat base of the Canadian Hospitals Injury Reporting and Prevention Program. Pediatrics 1994; 94 (suppl 6, part 2): $1041-3$.

12 Kopjar B, Wickizer T. How safe are day care centers? Day care versus home injuries among children in Norway. Pediatrics 1996; 97: 43-7.

13 Office of Financial Management. Washington State 1993 data book. Olympia, WA: Washington State, 1994.

14 Washington Administrative Code, 1995. \$388-155-010.

15 Thacker SB, Addiss DG, Goodman RA, Holloway BR Spencer HC. Infectious diseases and injuries in child day care. Opportunities for healthier children. $\mathcal{f} A M A 1992$ 268: $1720-6$

16 Breslow NE, Day NE. Statistical methods in cancer research Volume II - the design and analysis of cohort studies. Lyon, France: International Agency for Research on Cancer, 1987.

17 Greenland S. Dose-response and trend analysis in epidemiology: alternatives to categorical analysis. Epidemiology 1995; 6: 356-65.

18 Sacks JJ, Holt KW, Holmgreen P, Colwell LS, Brown JM Jr. Playground injuries in Atlanta child care centers. $A m \mathcal{F}$ Public Health 1990; 80: 986-8.

\section{US Congress kills national speed limits}

As noted elsewhere, a new act repealing the maximum national speed limit in the US is likely to lead to 'an immediate jump in both travel speeds and crash deaths'. This is what happened in 1987 when states were permitted to raise speed limits on ural interste highways to $65 \mathrm{mph}$.

\section{... And motorcycle helmet use laws??}

The laws may also be at risk from the same legislation by permitting states to repeal or weaken existing laws in response to congressional abandonment of federal incentives.

\section{... But the good news is less DWI??}

The new highway safety law creates an incentive for states to combat alcohol impaired driving among underage drinkers by insisting on 'zero tolerance', under penalty of losing 5 to $10 \%$ of their federal highway funds (Status Report 1996; 31: 1). 